\title{
Estudo das artérias coronárias no coração transplantado
}

Ivo A. NESRALLA*, Joāo Ricardo SANT'ANNA* Paulo Roberto PRATES*, Fernando A. LUCCHESE*, Renato A. K. KALIL*, Edemar M. PEREIRA*, Altamiro R. COSTA*, Martinez ROSSI*, Cláudio MORAES*, Marisa F. SANTOS*, Blau F. SOUZA*

RBCCV 44205-146

NESRALlA, I.A.; SANT'ANNA, J.R.; PRATES, P.R.; LUCCHESE, F. A.; KALIL, R.A.K.; PEREIRA, E. M.; COSTA, A. R.; ROSSI, M.; MORAES, C.; SANTOS, M. F.; SOUZA, B. F. - Estudo das artérias coronárias no coração transplantado. Rev. Bras. Cir. Cardiovasc., 6(3):158-166, 1991.

RESUMO: No período de junho de 1984 a dezembro de 1990, 16 pacientes portadores de insuficiência cardíaca terminal foram submetidos a transplante cardíaco ortotópico. A idade variou de dez dias a 54 anos, sendo 14 pacientes do sexo masculino e dois do sexo feminino. Desse grupo, seis $(37,5 \%)$ pacientes foram estudados anualmente através de cinecoronarioventriculografia, para avaliação do padräo evolutivo coronário, por período de dois a seis anos de evoluçāo. A idade dos doadores foi de 18 mais ou menos três anos. Em quatro dos seis pacientes pôde-se fazer estudo comparativo com a cinecoronarioventriculografia do doador, realizada por ocasiāo da avaliação pré-operatória. A análise morfométrica comparativa, em exames seriados, nāo mostrou lesōes proximais ou distais na rede coronária em nenhum dos pacientes da série. A funçāo ventricular foi normal, embora fossem identificados em todos os pacientes graus variáveis de hipertrofia de ventrículo esquerdo. Conclusōes: 1) A doença coronária, embora freqüente em coraçōes transplatados, não foi verificada na presente série. 2) A idade precoce dos doadores pode ter sido fator decisivo, assim como o emprego do esquema tríplice para o controle da rejeiçảo. 3) A cinecoronarioventriculografia tem importância no seguimento dos pacientes transplantados, podendo orientar na indicaçäo de novo transplante cardíaco ou angioplastia transluminal percutânea.

DESCRITORES: transplante cardíaco, aterosclerose coronária.

\section{INTRODUÇÃO}

A doença coronária no paciente submetido à transplante cardíaco constitui a maior limitação à sobrevida a longo prazo ${ }^{4}$. A incidência de coronariopatia no transplantado chega a $17 \%$ no primeiro, $26 \%$ no segundo e $40 \%$ no terceiro ano pós-transplante, o que coincide com a experiência da Universidade de Stanford $1,2,8,10$.

A rejeição crônica, associada à reação imunológica ao nível do endotélio coronáriano, constitui o principal fator determinante da lesão vascular. Outras causas são também apontadas, tais como hipercolesterolemia, aumento da agregação plaquetária, hipertensão arterial sistêmica e uso de esteróides, ciclosporina e outros (Figura 1).

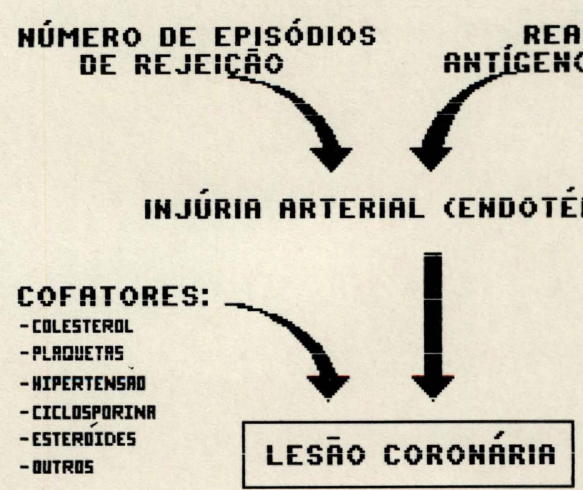

Fig. 1

Trabalho realizado no Instituto de Cardiologia do Rio Grande do Sul. Fundação Universitária de Cardiologia. Porto Alegre, RS, Brasil. Apresentado ao $18^{\circ}$ Congresso Nacional de Cirurgia Cardíaca. Rio de Janeiro, RJ, 5 e 6 de abril, 1991.

* Do Instituto de Cardiologia do Rio Grande do Sul, Fundação Universitária de Cardiologia.

Endereço para separatas: Ivo A. Nesralla. Av. Princesa Isabel, 395. 90620 Porto Alegre, RS, Brasil. 
NESRALLA, I.A.; SANT'ANNA, J.R.; PRATES, P.R.; LUCCHESE, F. A.; KALIL, R.A.K.; PEREIRA, E. M.; COSTA, A. R.; ROSSI, M.; MORAES, C.; SANTOS, M. F.; SOUZA, B. F. - Estudo das artérias coronárias no coraçāo transplantado. Rev. Bras. Cir. Cardiovasc., 6(3):158-166, 1991.

Apesar disto, a qualidade de vida dos transplantados é boa, registrando-se até 17 anos de sobrevida.

O presente estudo procura a importância da cinecoronariografia seriada no coração transplantado, comparando com o padräo coronariográfico no momento da doação.

\section{CASUÍSTICA E MÉTODOS}

\section{População}

No período de junho de 1984 a dezembro de 1990, 16 pacientes foram submetidos a transplante cardíaco ortotópico no Instituto de Cardiologia/Fundaçāo Universitária de Cardiologia. Os pacientes tinham idade entre 10 dias e 52 anos e 14 eram do sexo masculino e dois do sexo feminino, sendo todos de cor branca.

A etiologia era cardiopatia isquêmica em sete $(43,75 \%)$ casos, sendo que três pacientes haviam sido previamente submetidos à cirurgia de revascularização miocárdica, miocardiopatia dilatada em oito $(50 \%)$ e cardiopatia congênita (hipoplasia de ventrículo esquerdo) no restante $(6,25 \%)$.

Todos os pacientes apresentaram-se em classe funcional IV da NYHA e permanceram aguardando a cirurgia por um período que variou de 30 a 120 dias.

\section{Critérios de Indicação}

Os pacientes foram submetidos a criteriosa avaliação clínica e psicológica para aceitação no programa de transplante cardíaco (TC). Tivemos como critérios clínicos (TABELA 1): idade inferior a 55 anos, classe funcional IV (NYHA), expectativa de vida inferior a seis meses; ausência de hepatopatias, nefropatias, doenças sistêmicas (como colagenoses e diabetes mélito) e úlcera péptica ativa; ausência de infarto pulmonar nos últimos dois meses; não ser alcoólatra ou psicopata e não apresentar qualquer doença capaz de contra-indicar o uso de agentes imunossupressores.

Devido a intensidade do compromisso profissional e dos custos implicados, considerou-se fundamental que o paciente mostrasse condições emocionais estáveis e um adequado sistema de apoio, a fim de suportar as etapas envolvidas no procedimento cirúrgico.

\section{Seleção de Doadores}

Os doadores em potencial foram selecionados pelos seguintes critérios: idade inferior a 40 anos; morte cerebral comprovada por exame clínico-neurológico e por angiografia cerebral (com relatório assinado por neurologista do Hospital e independente da equipe de transplantes); compatibilidade $A B O$ com o receptor; equivalência de peso corporal (aceitando-se variaçōes de 20\%); "Crossmatch" ne-

TABELA 1

CRITÉRIOS DE SELEÇÃO

Receptor

1 - Idade inferior a 55 anos.

2 - Classe funcional IV (NYHA)

3 - Ausência de infecçōes

4 - Sobrevida menor de seis meses

5 - Ausência de hepatopatia, nefropatia, doença sistêmica

6 - Ausência de infarto pulmonar nos últimos dois meses

7 - RAP menor que $6 \cup \mathrm{Wood} / \mathrm{m} 2$

8 - Näo ter DPOC

9 - Não ser alcoólatra

10 - Não ser psicopata

11 - Ausência de úlcera péptica ativa

12 - Ter boas condiçōes sócio-econômicas
Doador

1 - Idade inferior a 40 anos

2 - Morte cerebral comprovada

3 - Compatibilidade "ABO"

4 - Equivalência de peso corporal

5 - Ausência de infecçöes

6 - Ausência de cardiopatia

7 - "Crossmatch" negativo

8 - Nảo depender de altas doses de droga inotrópica positiva

9 - Nenhum episódio de PA=zero

10 - Ausência de traumatismo torácico-cardíaco

11 - Nenhum episódio de PCR

${ }^{\star}$ RAP $=$ Resistência arterial pulmonar; ${ }^{\star \star} P C R=$ Parada cardiorespiratória; $D P O C=$ Doença pulmonar obstrutiva crônica. 
NESRALlA, I.A.; SANT'ANNA, J.R.; PRATES, P.R.; LUCCHESE, F. A.; KALIL, R.A.K.; PEREIRA, E. M.; COSTA, A. R.; ROSSI, M.; MORAES, C.; SANTOS, M. F.; SOUZA, B. F. - Estudo das artérias coronárias no coraçāo transplantado. Rev. Bras. Cir. Cardiovasc., 6(3):158-166, 1991.

gativo; ausência de infecção em qualquer subsistema; ausência de doença cardíaca (história familiar, exame físico, ECG, Rx, CVB, ecocardiograma e estudo hemodinâmico nos pacientes com mais de 35 anos); ausência de traumatismo torácico-cardíaco ou realização de massagem cardíaca externa; não estar na dependência de altas doses de vasopressores e não ter apresentado episódio prolongado de hipotensão arterial (Tabela 1).

A idade dos doadores variou de 36 horas de vida (criança com anencefalia) a 22 anos de idade. Os quatro primeiros doadores da presente série foram estudados por cinecoronariografia, para futura análise prospectiva da circulação coronária ( $\mathrm{Fi}$ gura 2A).

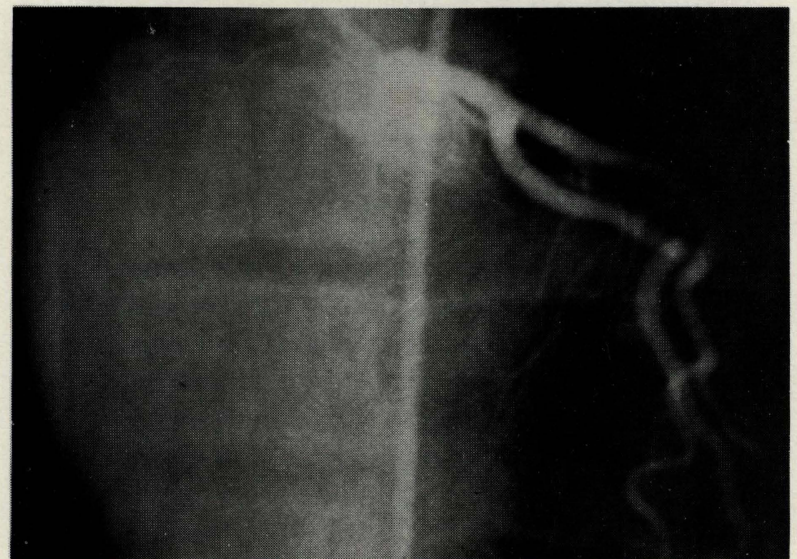

Fig. 2A - Coronária esquerda do doador com ausência de lesões parietais.

\section{Acompanhamento Pós-Operatório}

Nos dois primeiros pacientes o esquema de supressão associou ciclosporina $A$ e corticóide, e nos demais nove foi utilizado esquema tríplice, com ciclosporina A, corticóide e azatioprina.

Para detecção de episódios de rejeição usamos a biopsia endomiocárdica, por ser método de maior sensibilidade (quando comparado a exame físico, ECG e ecocardiograma), para a quantificação histológica do grau de rejeição (LEVE, MODERADA E SEVERA) a classificação da Dra. Billingham (Tabelas 2 e 3). O esquema de biopsia foi: semanal - nos primeiros 30 dias de $\mathrm{PO}$; quinzenal no segundo e terceiro mês de $\mathrm{PO}$; mensal do quarto ao sexto mês de PO; e bimestral após.

Sempre que ocorreram epsódios de rejeição moderada a severa foi feita pulsoterapia com metilprednisolona, na dose de $1 \mathrm{~g} \mathrm{EV}$ por dia, durante três dias consecutivos e a biopsia foi repetida aos sete dias para avaliação da terapêutica.

\section{TABELA 2}

CRITÉRIOS DE REJEIÇÃO - DRA. BILLINGHAM²

Leve: infiltrado linfocitário pericapilar e endocárdico

Moderada: infiltrado linfocitário intersticial; necrose miocítica focal e ocasional neutrofilia

Severa: infiltrado linfocitário intersticial; necrose miocítica difusa e proeminente neutrofilia

TABELA 3

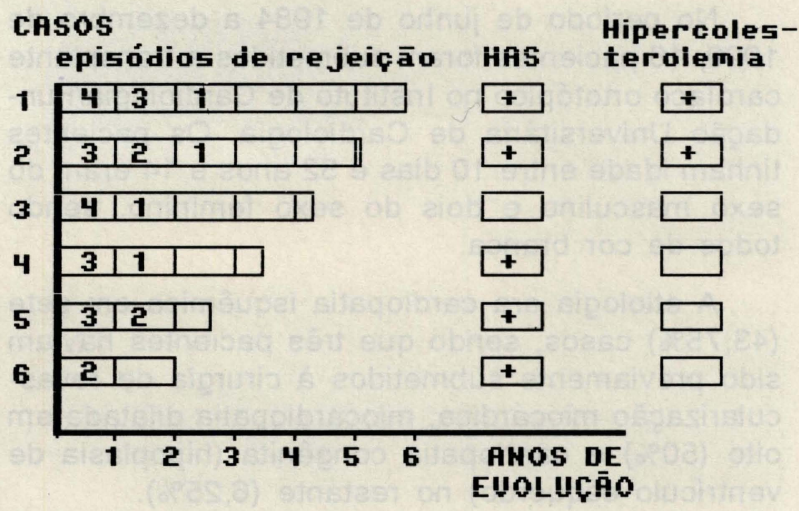

\section{Morfologia e Morfometria Arterial Coronária}

Da série de 16 pacientes submetidos a transplante cardíaco, os seis $(37,5 \%)$ doentes com maior tempo de seguimento foram considerados neste estudo. Eles haviam sido submetidos a cinecoronariografia e ventriculografia esquerda a intervalos anuais, compreendendo um período mínimo de dois anos e máximo de seis anos, para avaliação do padrão evolutivo das artérias coronárias e da função miocárdica.

Previamente ao transplante cardíaco, os coraçōes utilizados em quatro destes pacientes haviam sido submetidos à cinecoronariografia visando evidenciar a normalidade da circulação coronária.

A avaliação seqüencial do diâmetro das artérias coronárias de médio calibre foi realizada por um mesmo examinador, que desconhecia a evolução clínica dos pacientes. O calibre do cateter utilizado na cinecoronariografia foi utilizado como referência e as artérias avaliadas em seu diâmetro na origem e a cada dois centímetros de sua extensão.

Os dados obtidos foram tabulados e submetidos à análise estatística pelo teste $t$ de Student, considerando-se um valor crítico de $5 \%$. 
NESRALlA, I.A.; SANT'ANNA, J.R.; PRATES, P.R.; LUCCHESE, F. A.; KALIL, R.A.K.; PEREIRA, E. M.; COSTA, A. R.; ROSSI, M.; MORAES, C.; SANTOS, M. F.; SOUZA, B. F. - Estudo das artérias coronárias no coração transplantado. Rev. Bras. Cir. Cardiovasc., 6(3):158-166, 1991.

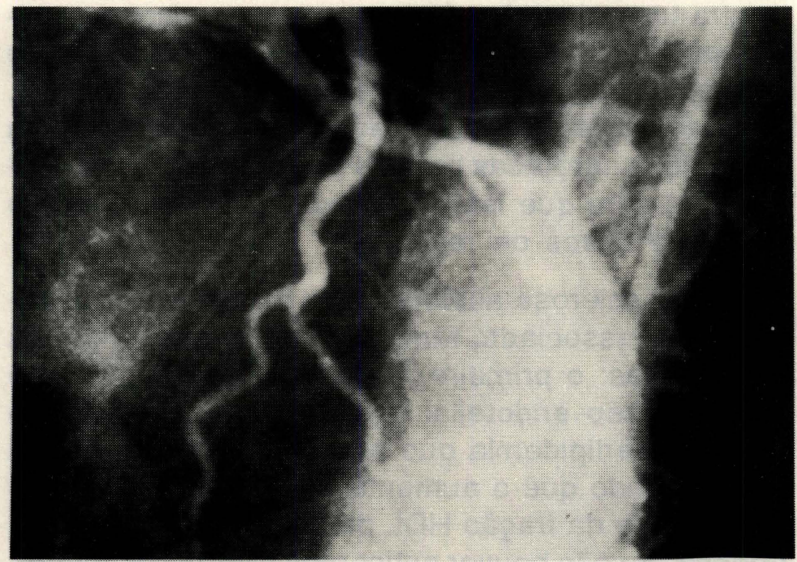

Fig. 2B - Coronária esquerda após seis anos do transplante, mostrando lesões parietais.

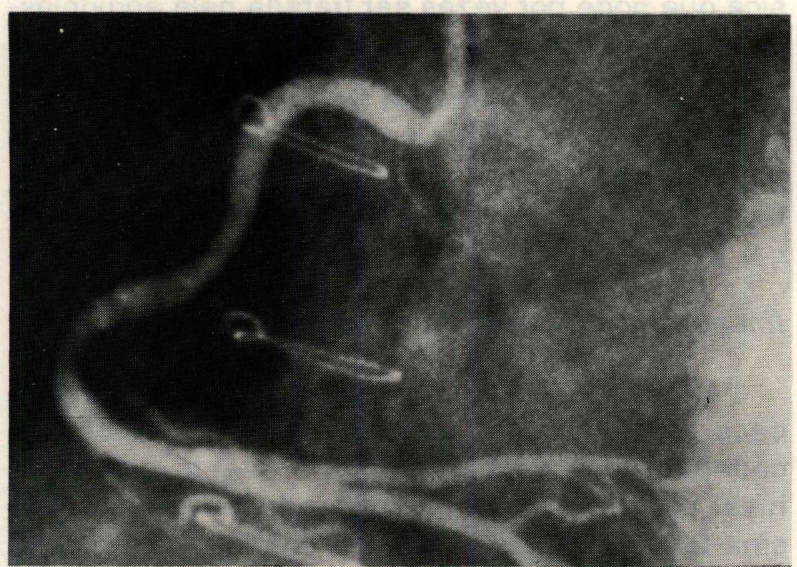

Fig. 2C - Coronária direita com lesões mínimas $(30 \%)$ no terço médio e irregularidade parietal distal após seis anos de transplante.

\section{RESULTADOS}

\section{Morfologia e Morfometria Arterial Coronária}

A : nálise destes parâmetros mostrou que não houve alteração significativa do diâmetro dos vasos coronários.

A análise dos chamados grandes vasos coronários mostra, conforme Figuras $2 \mathrm{~B}$ e $2 \mathrm{C}$, no paciente de número 1, alteraçōes parietais caracterizadas angiograficamente, mas que não determinam redução da luz do vaso. Tais achados usualmente são observados em aterosclerose coronária, na fase não obstrutiva, em que o processo degenerativo está confirnado apenas à parede, sem o componente obstrutivo mecânico.

A função ventricular avaliada através do cálculo da fração de ejeção e da pressão diastólica final $(\mathrm{Pd} 2)$ do ventrículo esquerdo, mostrou valores dentro da normalidade (Figura 2D e 2E).

\section{Episódios de Rejeição}

Os episódios de rejeição ocorreram, predominantemente, nos seis primeiros meses. $O$ paciente de número 6 da série apresentou apenas dois episódios de rejeição.

A hipertensão arterial sistêmica (HAS) esteve presente em cinco dos seis pacientes (TABELA 3).

Os pacientes de números 1 e 2 mostraram associação de HAS e hipercolesterolemia.
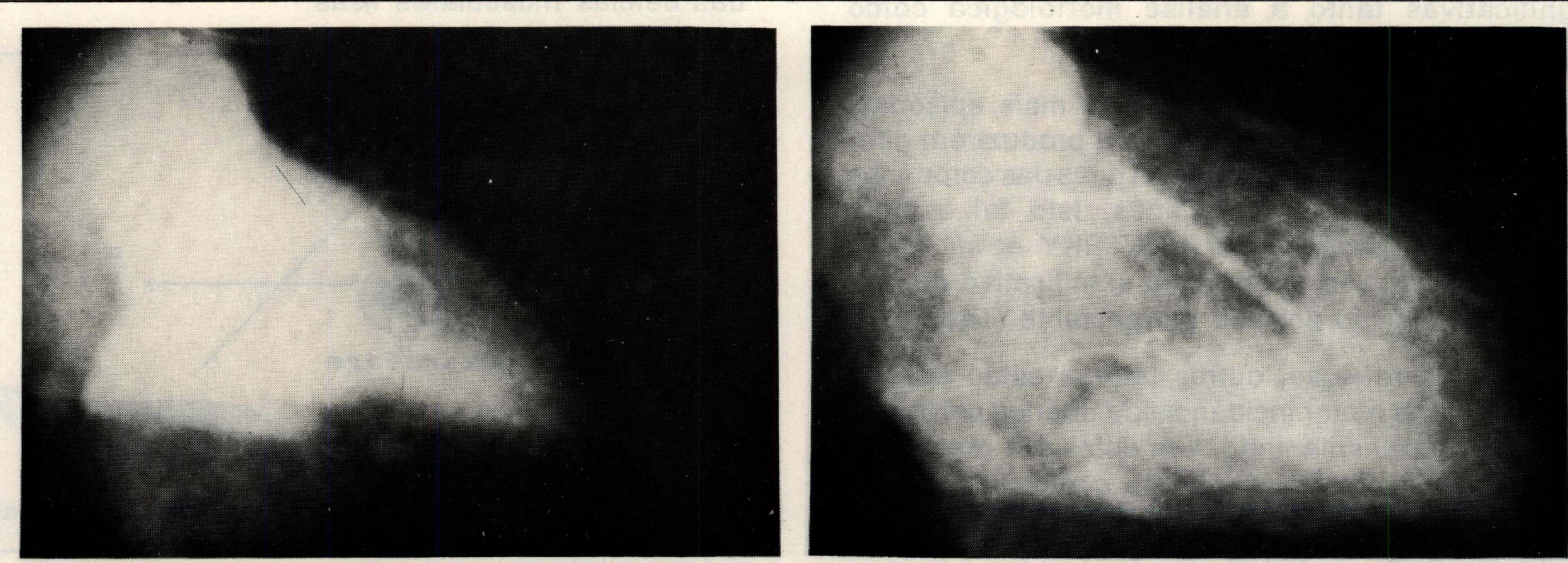

Fig. $2 \mathrm{D}$ e $2 \mathrm{E}$ - Ventrículo esquerdo em sístole e diástole não mostrando alteração da fração de ejeção. 
NESRALLA, I.A.; SANT'ANNA, J.R.; PRATES, P.R.; LUCCHESE, F. A.; KALIL, R.A.K.; PEREIRA, E. M.; COSTA, A. R.; ROSSI, M.; MORAES, C.; SANTOS, M. F.; SOUZA, B. F. - Estudo das artérias coronárias no coraçäo transplantado. Rev. Bras. Cir. Cardiovasc., 6(3):158-166, 1991.

\section{DISCUSSĀO}

As alteraçōes vasculares no coração transplantado são de dois tipos:

A) Rejeição crônica que determina espessamentos concêntricos da íntima, enquanto as camadas média e elástica interna permanecem inalteradas. Compromete geralmente vasos de pequeno calibre. A lesão resultante aparece no angiograma como obstrução tubular.

B) Aterosclerose clássica com formação da placa de ateroma de localização excêntrica e comprometendo os grandes vasos coronários. São lesões passíveis de serem tratadas pela angioplastia coronária transluminal percutânea.

Embora o teste ergométrico em esteira e os estudos radioisotópicos como a ventriculografia de esforço com talium sejam métodos seguros para diagnosticar e/ou acompanhar a evolução da doença coronária em pacientes transplantados, a angiografia coronária permanece como o método mais preciso para avaliar as alteraçōes coronárias no coração transplantado; ela permite quantificar o grau de obstrução coronária e visibilizar vasos de até 200 micra de diâmetro. A biopsia miocárdica, útil no diagnóstico da rejeição e de suas repercussōes sobre - músculo cardíaco, tem papel limitado no diagnóstico da aterosclerose coronária, cujas alteraçōes se processam preferencialmente nos vasos epicárdicos.

$\mathrm{Na}$ presente série, comprovou-se apenas alteraçōes resultantes da rejeição crônica no paciente de número $1 \mathrm{com}$ seis anos de evolução, caracterizadas como discretas lesões tubulares nas pequenas artérias coronárias. Não havia comprometimento da função ventricular nos casos analisados (Figura 2).

Os demais pacientes não apresentaram lesōes significativas tanto à análise morfológica como morfométrica da árvore coronária.

Está demonstrado que dois ou mais episódios de rejeição já são suficientes para produzirem diferentes graus de lesões em uma ou duas das coronárias no período de um a três anos. Isto foi estatisticamente comprovado por URETSKY et alii ${ }^{\bullet}$. Em nossa série, houve um número significativo de episódios de rejeição por ano por paciente (Tabela 3).

Além da rejeição, outros fatores estão associados com uma maior incidência de doença coronária no paciente transplantado. Um deles é a reação do antígeno DR com os anticorpos citotóxicos produzidos pelas células $B^{5}$. Daí a importância da tipagem prévia do HLA.

Realizamos o "Crossmatch" no pré-operatório contra um painel de células, para pesquisar os anticorpos pré-formados e, no pós-operatório, para análise retrospectiva. Nenhum dos resultados foi positivo. Dois dos seis pacientes haviam sido submetidos a operaçōes cardíacas prévias (revascularizaçāo miocárdica) sem que isto tenha produzido um número maior de crises de rejeição.

Aterosclerose acelerada no paciente transplantado está associada, também, a dois outros fatores importantes: o primeiro, a reação imunológica que produz lesão endotelial; o segundo, a associação com a hiperlipidemia que acelera a doença ${ }^{5}$. Está demonstrado que o aumento do colesterol total e o decréscimo da fração HDL predispõe à evolução da doença. Se não houver anticorpos citotóxicos, prodtuzidos pelas células $B, a$ aterosclerose do enxerto ocorre mais tardiamente (após três anos), progride lentamente com produção de placa de ateroma clássica que pode por vezes ser tratada pela angioplastia transluminal percutânea.

No entanto, quando os dois fatores estão associados, a doença tem um curso maligno, com aparecimento precoce da lesão com obstrução concêntrica das coronárias (lesão tubular) e morte súbita.

\section{Imunologia das Lesões Endoteliais}

A lesão do endotélio e da célula muscular lisa decorre fundamentalmente de três eventos desencadeados em série. O primeiro evento ocorre ao nível dos linfócitos $T$, com produção da interleucina-2 (IL-2), ativação da interleucina 1 e ativação do sistema interferon, com alteraçōes na capacidade adesiva dos leucócitos e do processo de coagulação.

O segundo episódio ocorre ao nível dos macrófagos e resulta na liberação de IL-1 e IL-6, o que altera a quimiotaxia dos leucócitos, com proliferação das células musculares lisas.

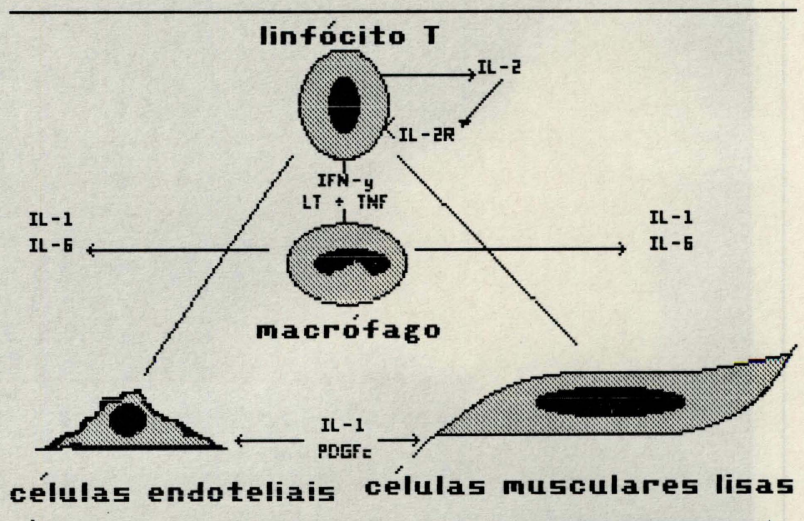

Fig. 3 - Imunologia das lesões endoteliais IL = interleucina; IFN = interferon; PDGF = fator de agregação plaquetária. 
NESRALlA, I.A.; SANT'ANNA, J.R.; PRATES, P.R.; LUCCHESE, F. A.; KALIL, R.A.K.; PEREIRA, E. M.; COSTA, A. R.; ROSSI, M.; MORAES, C.; SANTOS, M. F.; SOUZA, B. F. - Estudo das artérias coronárias no coração transplantado. Rev. Bras. Cir. Cardiovasc., 6(3):158-166, 1991.

O terceiro episódio, como efeito cascata, ocorre nas células endoteliais e musculares lisas. Há proliferação de células mesenquimais mediadas por um peptídio resultante de um fator derivado da alteração plaquetária (PDGF) com produção de imunoglobulina. Estes eventos atuam sobre o endotélio, resultando na lesão de suas células ${ }^{2,6-8}$.

A imunologia das lesões endoteliais está expressa na Figura 3.

\section{Ação das Drogas Imunossupressoras}

As alteraçōes coronárias são também resultantes da medicação imunossupressora, principalmeṇte de altas doses de CsA, esta foi administrada nos primeiros pacientes de nossa série na dose de 15 a $17 \mathrm{mg} / \mathrm{kg} / \mathrm{dia}$ (casos 1 e 2). Mas já há quatro anos empregamos o esquema tríplice, com baixas doses de CsA ( $<5 \mathrm{mg} / \mathrm{kg} / \mathrm{dia}$ ) associada a baixas doses de azatioprina e corticóides. Acreditamos que isto resultou favorável na profilaxia da enfermidade coronária do transplantado cardíaco e facilitou o controle da hipertensão arterial sistêmica (HAS) conseqüente ao efeito colateral da CsA.

Outro fator que pode reduzir o número de episódios de rejeiçāo no $\mathrm{PO}$ imediato é o uso profilático do soro antilinfocitário (ATG) diminuindo a freqüência de pulsoterapia com altas doses de metilpredinisolona.
Como medicação coadjuvante empregamos aspirina e dipiridamol, cujos efeitos profiláticos sobre a progressão da aterosclerose coronária já são conhecidos.

Recomendamos ainda a pesquisa de infecção por Citomegalovirus já na fase pré-transplante. Pois sua presença tem contribuição significativa para evolução da lesão coronária do transplantado.

A idade do doador desempenha papel importante na evolução da lesão vascular. Por isto, sempre que possível, devemos selecionar doadores jovens. $\mathrm{Na}$ nossa experiência a idade variou de 15 a 21 anos, o que consideramos fator favorável.

\section{CONCLUSÕES}

1) A doença coronária, embora freqüente em coraçōes transplantados, nāo foi verificada na presente série, que compreendeu período de observação entre dois e seis anos após transplante.

2) $A$ idade precoce dos doadores pode ter sido fator decisivo, assim, como o emprego do esquema tríplice para o controle da rejeição.

3) A cinecoronarioventriculografia tem importância no seguimento dos pacientes transplantados, podendo inclusive orientar na indicação de novo transplante cardíaco ou de angioplastia transluminal percutânea.

NESRALla, I. A.; SANT'ANNA, J. R.; PRATES, P. R.; LUCCHESE, F. A.; KALIL, R. A.K.; PEREIRA, E. M.; COSTA, A. R.; ROSSI,M.; MORAES, C.; SANTOS, M. F.; SOUZA, B. F. - Coronary atherosclerosis following heart transplantation. Rev. Bras. Cir. Cardiovasc., 6(3):158-166, 1992.

ABSTRACT: Late post-operative serial coronariographic evaluation was performed in a series of 6 patients submitted to cardiac transplantation. They were part of a series of 16 patients operated on from June 1984 to December 1990. Their age were from 10 days to 54 years, 14 male and 2 female. The followup time was from 2 to 6 years. The cineangiograms were performed yearly for coronary pattern evolutive evaluation. The mean donor age was $18 \pm 3$ years. In 4 patientes it was possible to compare late results with the preoperative donor cinecoronaryangiogram. The comparative morphometric analysis, at serial examination did not reveal any proximal or distal coronary lesion in any patient. Left ventricular function was considered normal, but varied degrees of myocardial hypertrophy were present in all patients. In conclusion: 1) coronary artery disease, although frequent in transplanted hearts, was not present in this series; 2) early donor age could have been an important factor, as well as the immunossupressive regime emploied; 3) cinecoronary ventriculoangiogram is important for follow-up of transplanted patients, and could eventually orient for retransplantation.

DESCRIPTORS: heart transplantation, coronary atherosclerosis. 
NESRALLA, I.A.; SANT'ANNA, J.R.; PRATES, P.R.; LUCCHESE, F. A.; KALIL, R.A.K.; PEREIRA, E. M.; COSTA, A. R.; ROSSI, M.; MORAES, C.; SANTOS, M. F.; SOUZA, B. F. - Estudo das artérias coronárias no coraçāo transplantado. Rev. Bras. Cir. Cardiovasc., 6(3):158-166, 1991.

\section{REFERÊNCIAS BIBLIOGRÁFICAS}

1 BIEBER, C.P.; HUNT, S. A.;SCHWINN, D. A.; JAMIESON, S. A.; REITZ, B. A.; OYER, P. E.;SHUMWAY, N. E.; STINSON, E. B. - Complications in longterm survivors of cardiac transplantation. Transpl. Proc., 13:207-211, 1981.

2 BILLINGHAM, M. E. - Cardiac transplant atherosclerosis. Transpl. Proc., 19(Supl. 5):19-25, 1987.

BILLINGHAM, M. E. - Diagnosis of cardiac rejection by endomyocardial biopsy. J. Heart Transpl., 1:2530, 1982.

4 GRIEPP, R. B.; STINSON, F. B.; BIEBER, C. P.; REITZ, B. A.; COPELAND, J. G.; OYER, P. E.; SHUMWAY, N. E. - Control of graft arteriosclerosis in human heart transplant recipients. Surgery, 81:262-268, 1977.

5 HESS, M. L.; HASTILLO, A; MOHANALIMAR, T. Accelerated atherosclerosis in cardiac transplantation: role of cytoxic B-cell antibodies and hyperlipidemia. Circulation, 68 (Supl. 2):94-101, 1983.

6 HRUBAN, R. H.; BESCHORNER, W. E.; BAUMGARTNER, W. A.; AUGUSTINE, S. M.;REITZ, B. A.; HUTCHINS, G. M. - Accelerated arteriosclerosis in heart transplant recipients: an immunopathology study of 22 transplanted hearts. Transpl. Proc., 1:1230-1232, 1991.

7 LIBBY, P.; SALOMON, R. N.; PAYNE, D. D.; SCHOEN, F. J.; POBER, J. S. - Functions of vascular wall cells related to development of transplantation-associated coronary arteriosclerosis. Transpl. Proc. 4:3677. 3684, 1989

OGUMA, S.; OKAZAKI, H.; JIMBO, M.; IGUCHI, A.; TAKAHASHI, H.; ISHIZAKI, M. - Vascular rejection and arteriosclerosis. Transpl. Proc. 4:(Supl. 5), 63-70, 1987.

URETSKY, B. E.; MURALI, S.; REDDY, P. S. - Development of coronary artery disease in cardiac transplant patients receiving immunosuppressive therapy with cyclosporine and prednisone. Circulation, 76:827-830, 1987.

10 ZUSMAN, D. R.; STINSON, E. B.; OYER, P. E. determinants of accelerated graft atherosclerosis (AGAS) in conventional and cyclosporine treated heart transplant recipients. J. Heart Transpl., 4:587-590, 1985.

\section{Discussão}

\section{DR. NOEDIR STOLF}

São Paulo, SP

O trabalho do Dr. Nesralla e colaboradores traz à discussão um assunto de grande importância no campo do transplante cardíaco. Vários avanços especialmente a introdução da ciclosporina diminuíram a letalidade da rejeição e da infecção, de sorte que a aterosclerose coronária no coração transplantado é a principal limitação à sobrevivência tardia do paciente transplantado. A análise das maiores séries da literatura mostra incidência desse tipo de complicação variando de 5 a $18 \%$ ao fim de um ano, de 15 a $27 \%$ ao fim de dois anos, 20 a $44 \%$ em três anos e perto de $50 \%$ em cinco anos. Em nossa experiência de 73 transplantes cardíacos estudamos 22 com evolução de um ou mais anos através de cateterismo, cinecoronariografia e cineventriculografia. Em relação ao estudo das coronárias, dois hemodinamicistas estudaram os filmes em busca de lesōes mesmo discretas. Com esse tipo de análise - número de pacientes com lesão coronária, que parecia pequeno, cresceu. Nós verificamos que ao fim de um ano $68 \%$ dos pacientes têm coronárias normais; aos dois anos, $59 \%$; aos três anos, $44 \%$ e nos quatro anos apenas $40 \%$ têm coronárias normais. Observa-se, no entanto, que alteraçōes coronárias maiores estão presentes apenas em $5 \%, 8 \%, 14 \%$ e $20 \%$, respectivamente, ao fim de um, dois, três e quatro anos após o transplante. Em relação à função ventricular, verificamos que função normal estava presente em $86 \%, 82 \%, 58 \%$ e $20 \%$ ao fim, respectivamente, de um ano, dois anos, três anos e quatro anos. Nós não encontramos relação entre doença coronária e idade dos receptores e doadores, níveis de colesterol ou triglicérides, presença de hipertensão, diagnóstico da cardiomiopatia. Quanto à análise da casuística apresentada pelo Dr. Nesralla, acreditamos que a ausência de coronariopatia grave e apenas um caso de coronoriopatia leve podem ser explicados mais pelo número pequeno de pacientes do que pela idade dos doadores e pelo esquema de imunossupressão, fatores estes que já se demonstrou não influem no aparecimento da doença coronária pós-transplante.

\section{DR. FERNANDO ANTÔNIO FANTINI Belo Horizonte, MG.}

Primeiramente, gostaria de agradecer à Comissão Organizadora pela honra de poder participar do nosso Congresso, quanto mais pela chance de comentar este trabalho apresentado de forma excelente pelo Dr. Nesralla e seu grupo. O tema abordado, complexo e ainda não completamente elucidado, tem sido motivo de extensas pesquisas propiciando um grande número de publicaçōes. $\mathrm{Na}$ literatura recente destacam-se "descriçōes" de formas de rejeição vascular medidas por sistemas antigênicos presentes na superfície das células endoteliais quais sejam o sistema HLA-A, B e DR e o sistema endotélio monócito. Este último tem-se mostrado de fundamental importância pois mesmo com HLA $100 \%$ idêntico e Crossmatch negativo podem ocorrer rejeiçöes vasculares mediadas por esse sistema, como 
NESRALLA, I.A.; SANT'ANNA, J.R.; PRATES, P.R.; LUCCHESE, F. A.; KALIL, R.A.K.; PEREIRA, E. M.; COSTA, A. R.; ROSSI, M.; MORAES, C.; SANTOS, M. F.; SOUZA, B. F. - Estudo das artérias coronárias no coraçāo transplantado. Rev. Bras. Cir. Cardiovasc., 6(3):158-166, 1991.

tem sido demonstrado em transplantes renais de doadores vivos. Aliam-se a estas alteraçōes outros fatores como a presença de dislipidemias e alteraçōes protombóticas nos pacientes transplantados, assim como infecção ou reativação de doença citomegalovirótica e a ocorrência de fenômenos de rejeição de repetição como já citado pelo autor. Assim, as pesquisas parecem apontar uma causa imunológica como o fator predisponente para o aparecimento da doença, o que nos faz crer que a seleção de doadores jovens não seja um fator primordial na prevenção da lesão. Além disso trabalhos recentes, como o resultado multicêntrico dos hospitais filiados do estado americano de Utah, com larga série de pacientes não relacionam a idade do doador ou do receptor como fator de risco para o desenvolvimento de lesōes coronárias no coração transplantado. Neste sentido, o grupo de transplantes do Hospital Biocor de Belo Horizonte, tem dado uma ênfase toda especial à avaliação imunológica pré transplante. Painel de células e painel cultura de linfócitos são testes realizados com todos os candidatos a receptor. No pré transplante imediato são feitos o Crossmatch e o HLA AB. Realizamos ainda pesquisas sorológicas para citomegalovírus, HIV, hepatite e Chagas no doador e no receptor. Outra conclusão extraída do presente trabalho é a de que a angiografia permanece como - melhor método para avaliar as possíveis alteraçōes coronárias no coração transplantado. Concordamos com o Dr. Ivo que ele seja o melhor, muito embora não exclua a presença de lesão coronária. Gostaríamos de chamar a atenção para um caso extraído da nossa casuística, que, abrangendo o período de julho de 1988 a março de 1991, conta com 25 pacientes operados com uma sobrevida de $72 \%$. O período de seguimento médio é de 15 meses e o máximo de 34 meses. Nove pacientes já foram submetidos a um estudo cinecoronariográfico e seis pacientes a dois estudos. O caso em questão é o de paciente do sexo masculino, de 58 anos, que era portador de cardiopatia isquêmica, previamente submetido à cirurgia de revascularização do miocárdio aos 39 anos e transplantado em 31.12.89. O doador tinha 29 anos e era do mesmo grupo sanguíneo. A avaliação imunológica pré-transplante mostrou que a reatividade do receptor contra um painel de células era negativo embora ele fosse um bom respondedor no painel CML. O HLA do doador era $A_{9} A_{10}$ $B_{5} B_{17}$ e do receptor $A$ A B , com Crossmatch negativo. Apresentou no $12^{\circ}$ dia de pós-operatório quadro de abdome agudo por perfuração intestinal tendo sido submetido a colectomia extensa e colostomia, com bom resultado. Cortes histológicos do intestino grosso mostraram a presença de inclusões para citomegalovírus. No $1^{9}$ ano pós transplante 0 paciente apresentou três espisódios de rejeição leve (grau I) pela Class Margareth Billigham. Este paciente foi submetido a estudo cinecoronariográfico de rotina em 04.02.91, que não mostrou qualquer lesão coronária. O paciente retornou ao hospital em $02.03,91$, ou seja três semanas após, com quadro de ICC franca e IAM anterior extenso ao ECG. Foi submetido a nova cine que mostrou oclusão de descendente anterior com extensa discinésia anterior, porém com evolução benigna até o momento. Embora não possamos comprovar histologicamente a lesão coronária, existem relatos na literatura de casos semeIhantes, inclusive com confirmação à necropsia como no trabalho apresentado por English do Papworth Hospital de Cambridge no Congresso da International Society for Heart Transplantation, em 1988. Três fatores indicados como relacionados à doença se destacam nesse caso: a falta de identidade do sistema HLA, doença citomegalovirótica e dislipidemia. Assim sendo, essa grave complicação, que, para a felicidade dos autores e apesar do título do trabalho, não foi observada na sua casuística é ao nosso ver multifatorial, mas iniciada após injúria endotelial imunomediada. Consideramos que a afirmação de que a baixa idade dos doadores é um fator decisivo na prevenção da doença coronária no coração transplantado carece de comprovação no presente trabalho e não encontra suporte na literatura mundial. Finalizando, gostaríamos que o Dr. Ivo nos desse maiores detalhes de sua casuística, como a ocorrência de mortalidade tardia, causas de óbito, ocorrência de morte súbita, etc. Gostaríamos, ainda, de saber os critérios para classificar os doadores como sendo jovem e se isto não tem limitado a procura de órgãos.

\section{DR. NESRALLA \\ (Encerrando)}

Agradeço aos colegas os comentários, que muito contribuem para complementar o trabalho, através da apresentação de suas experiências extensas na área. Duas questōes importantes foram levantadas quanto ao texto e merecem um esclarecimento. A baixa incidência de doença coronária (ou ausência) por nós encontrada seja decorrente do pequeno número de pacientes e não justificável pela idade dos doadores ou pelo esquema imunossupressor utilizado. Acreditamos que os pacientes avaliados sejam uma amostra representativa de nosso grupo de transplantados, que hoje alcança mais de 20 , considerando-se que o acompanhamento pós-operatório tem sido rigoroso e com adequada aderência por parte dos pacientes e que as medidas instituídas são aplicadas a todos. Entre estas rotinas está incluído um controle imunológico rígido e a seleção de doador preferencialmente jovem, bem como o tratamento precoce de episódios de rejeição. Assim, esperamos poder reproduzir os resultados obtidos nos 
NESRALLA, I.A.; SANT'ANNA, J.R.; PRATES, P.R.; LUCCHESE, F. A.; KALIL, R.A.K.; PEREIRA, E. M.; COSTA, A. R.; ROSSI, M.; MORAES, C.; SANTOS, M. F.; SOUZA, B. F. - Estudo das artérias coronárias no coraçäo transplantado. Rev. Bras. Cir. Cardiovasc., 6(3):158-166, 1991.

demais pacientes da série, cuja avalização não foi incluída no trabalho devido ao menor tempo de acompanhamento. Quanto ao papel da idade jovem do receptor como um dos fatores contribuintes para a baixa incidência de doença coronária, realmente não existe uma comprovação científica definitiva na literatura, devendo ser considerada como uma hipótese para justificar nossos achados, conforme citado no resumo do trabalho. Muito obrigado. 